\title{
DESCOLONIZAR JÁ: PONTOS EM DEBATES SOBRE O EPISTEMICÍDIO
}

Josimere Serrão Gonçalves

Pedagoga, Especialista em Coordenação e Organização do Trabalho Pedagógico; Especialista em Relações Raciais para o Ensino Fundamental. Técnica em Educação na rede estadual de ensino (SEDUC/PA). Integrante do Grupo Experimentações: Grupo de Estudos e Pesquisas em Currículo, Subjetividade e Sexualidade na Educação Básica (Campus Universitário de Abaetetuba/Baixo Tocantins-UFPA).E-mail: josi-goncalves@hotmail.com

\section{Maria Antonia Paixão Feitosa}

Mestranda no Programa de Pós-graduação em Cidades, Territórios e Identidades PPGCITI/CAAB/UFPA. Integrante do Grupo de Pesquisa Experimentações (Grupo de Estudos e Pesquisas em Currículo, Subjetividade e Sexualidade na Educação Básica) UFPA. E-mail: antoniapfeitosa@gmail.com

\section{RESUMO}

Este trabalho tem por objetivo discutir acerca da descolonização do saber, apontando como ao longo do processo de colonização de territórios, inúmeros conhecimentos foram negados, silenciados e por fim exterminados. Para esta incursão baseada na pesquisa bibliográfica, autores como Quijano (2005), Crenshaw (2004), Chimamanda (2017), Santos (2010) e Ribeiro (2017, 2018), Machado (2018) são referências para a abordagem ora proposta. Problematizar a questão do epistemicídio, contribuirá desta forma para que outras vozes possam ressoar.

PALAVRAS-ChAVE: Colonialidade. Epistemicídio do conhecimento. Descolonização do saber.

\section{DECOLONIZE NOW: POINTS IN DEBATES ABOUT EPISTEMICIDE}

\begin{abstract}
This work aims to discuss about the decolonization of knowledge, pointing out how throughout the process of colonization of territories, innumerable knowledge was denied, silenced and finally exterminated. For this incursion based on bibliographic research, authors such as Quijano (2005), Crenshaw (2004), Chimamanda (2017), Santos (2010) and Ribeiro (2017, 2018), Machado (2018) are references for the proposed approach. To problematize the issue of
\end{abstract}


epistemicide, will contribute in this way so that other voices can resonate.

KEYWORDS: Coloniality. Epistemicide of knowledge. Decolonization of knowledge.

\section{INTRODUÇÃO}

É possível o extermínio de um conhecimento? Ou então o desaparecimento de uma cultura? quais são os perigos de uma história única? As questões ora apresentadas são pontos de reflexão para que possamos dialogar em torno da colonialidade do saber e assim buscar romper com este padrão epistemológico que contribuiu para o silenciamento de vozes outras consideradas inferiores, insignificantes, marginais. Para este trajeto, sugerimos três pontos de atenção. No primeiro, faremos uma breve reflexão em torno da colonialidade do saber. No segundo, iremos realizar um apanhado acerca do epistemicídio. Fecharemos este debate com um diálogo em torno da necessidade da descolonização do saber como possibilidade para que outras histórias possam ser contadas.

\section{A COLONIALIDADE DO SABER: COLONIALISMO E DOMINAÇÃO CULTURAL}

O colonialismo pode ser considerado um dos processos mais violentos da história. Em busca de novos territórios para o estabelecimento e manutenção de seus impérios, os colonizadores não mediram esforços para não somente usurpar riquezas dos povos conquistados, mas considerando a soberania política imposta exerceram sua superioridade também por meio da dominação cultural como nos elucida Quijano.

os colonizadores exerceram diversas operações que dão conta das condições que levaram à configuração de um novo universo de relações intersubjetivas de dominação entre a Europa e o europeu e as demais regiões e populações do mundo, às quais estavam sendo atribuídas, no mesmo processo, novas identidades geoculturais. Em primeiro lugar, expropriaram as populações colonizadas -entre seus descobrimentos culturais- aqueles que resultavam mais aptos para o desenvolvimento do capitalismo e em benefício do centro europeu. Em segundo lugar, reprimiram tanto como puderam, ou seja, em variáveis medidas de acordo com os casos, as formas de produção de conhecimento dos colonizados, seus padrões de produção de sentidos, seu universo simbólico, seus padrões de expressão e de objetivação da subjetividade. A repressão neste campo foi reconhecidamente mais violenta, profunda e duradoura entre os índios da América ibérica, a que condenaram a ser uma 
subcultura camponesa, iletrada, despojando-os de sua herança intelectual objetivada. Algo equivalente ocorreu na África. Sem dúvida muito menor foi a repressão no caso da Ásia, onde portanto uma parte importante da história e da herança intelectual, escrita, pôde ser preservada. E foi isso, precisamente, o que deu origem à categoria de Oriente. Em terceiro lugar, forçaram -também em medidas variáveis em cada caso- os colonizados a aprender parcialmente a cultura dos dominadores em tudo que fosse útil para a reprodução da dominação, seja no campo da atividade material, tecnológica, como da subjetiva, especialmente religiosa. É este o caso da religiosidade judaico-cristã. Todo esse acidentado processo implicou no longo prazo uma colonização das perspectivas cognitivas, dos modos de produzir ou outorgar sentido aos resultados da experiência material ou intersubjetiva, do imaginário, do universo de relações intersubjetivas do mundo; em suma, da cultura (QUIJANO, 2005, p.121).

Neste contexto, populações colonizadas perderam o direito a posse de seus territórios e como se não fosse o suficiente seu patrimônio cultural e sua produção de conhecimento destinou-se a subalternidade, ao posto de uma subcultura, sem valor, sem herança intelectual, enfim, sem história.

A esta prática Quijano denomina de colonialidade. A colonialidade "é o conjunto de discursos, práticas que tem como principal objetivo a subalternização dos povos colonizados e a permanência da hegemonia da nação colonizadora" (QUIJANO, 2005). Neste viés foi também uma "dominação epistemológica" ( MENEZES E SANTOS, 2010), na qual o modus operandi do colonialismo suprimiu saberes de nações/povos colonizados.

A partir do momento em que determinados saberes passam a ser considerados legítimos, autorizados e com títulos de verdade, em detrimento a outros visto como desautorizados surge então a colonialidade do saber, que por sua vez perpetua-se na concepção de que a Europa está no centro da produção do conhecimento e os povos não-europeus ficam na outra parte em que seus saberes sofrem a apropriação cultural ou a negação cultural para a imposição de um conhecimento universalizante (DIAS apud RESTREPO; ROJAS , 2015). Suprimir saberes ou destruir conhecimentos locais consiste em um "epistemicidio". É o que problematizaremos a seguir.

\section{EPISTEMICÍDIO: NEGAÇÃO, OCULTAÇÃO E MORTE DO CONHECIMENTO}

Gonçalves (2005) na apresentação do livro em português "a colonialidade do saber: 
eurocentrismo e ciências sociais- Perspectivas latino-americanas"1 ${ }^{1}$ recorre a Walter Mignolo para discorrer sobre a diversidade epistêmica enquanto patrimônio da humanidade.

Como nos disse Walter Mignolo, o fato de os gregos terem inventado o pensamento filosófico, não quer dizer que tenham inventado $\mathrm{O}$ Pensamento. O pensamento está em todos os lugares onde os diferentes povos e suas culturas se desenvolveram e, assim, são múltiplas as epistemes com seus muitos mundos de vida. Há, assim, uma diversidade epistêmica que comporta todo o patrimônio da humanidade acerca da vida, das águas, da terra, do fogo, do ar, dos homens (GONÇALVES, 2005, p.5).

Para ilustrar este pensamento a respeito das múltiplas epistemes, na revista "Raça", o historiador Carlos Machado publicou em março de 2018 uma matéria intitulada "Invenções africanas que mudaram o mundo" 2 . Nesta matéria, uma frase sugestiva de reflexão para adentrar a temática inquieta o leitor logo de primeira: “Até que os leões contem a sua história, os contos de caça sempre glorificarão o caçador”. A frase de Chinua Achebe-(1930-2013) prepara o leitor para conhecer o outro lado da história, que pela apropriação e violência do colonialismo, do eurocentrismo deixaram de ser conhecidas ou foram alvos do epistemicídio operado pela dominação colonial.

Para Santos e Meneses (2010) a imposição de uma epistemologia dominante aconteceu porque foi amparada pela diferença cultural do mundo e também por uma diferenciação política do colonialismo e capitalismo existente. A partir destas práticas possibilitadas pela intervenção epistemológica dominante sustentada pela força militar, econômica e política impôs-se aos povos e culturas não-ocidentais um conhecimento universalizante que por sua vez contribui para o epistemicídio.

O epistemicídio significa a morte, a supressão de determinado conhecimento, saber, tradição, cultura. Por meio da instauração de um projeto de colonização que procurou homogeneizar o mundo e ao mesmo tempo incutir que os saberes não ocidentais eram saberes de ultima classe, inferiores. O epistemicidio foi resultado de uma "dominação epistemológica, uma relação extremamente desigual de saber-poder que conduziu à supressão de muitas formas de saber próprias dos povos e/ou nações colonizados” (SANTOS e MENESES, 2010, p.19).

1 Ver: LANDER, Edgardo ( Org). A colonialidade do saber: eurocentrismo e ciências sociais- Perspectivas latino americanas. Coleccion Sur Sur, CLACSO, Ciudad Autônoma de Buenos Aires, Argentina. 2005. Disponível em: http://bibliotecavirtual.clacso.org.ar/

2 Consultar : MACHADO, Carlos. Invenções africanas que mudaram o mundo. Revista Raça. 2018. https://revistaraca.com.br/invencoes-africanas-que-mudaram-o-mundo/ 
Então, embora não sejamos hoje um território colonizado, resquício desta colonização ainda permanece em nossos pensamentos, práticas, territórios e contextos. Isto é, a colonialidade do saber ainda domina ao produzir conhecimento seguindo uma visão de ciência aos moldes cartesiano, que imprimiu um conhecimento padrão que se apropriou/apropria de culturas, oculta saberes de territórios considerados inferiores para impor um conhecimento universalizante. Romper com estas correntes torna-se imperativo.

\section{DESCOLONIZAÇÃO DO SABER: POSSIBILIDADES PARA OUTRAS HISTÓRIAS}

Os contos de caça sempre glorificaram o caçador. Ao "caçador" é determinado o poder de contar os fatos, ele é o herói, o superior, o imbatível, o dono do discurso. Já o "leão" reserva-se o título de caça, o procurado, sem muitas possibilidades de vencer o caçador. No final, será vencido pelo cansaço e abatido pelo imponente caçador.

Mas se a história fosse outra e o "leão" pudesse contar a sua versão dos fatos: como seria?

Neste exercício Machado (2018) se coloca na posição de "leão" e apresenta na publicação "as invenções do continente africano que mudaram o mundo" já mencionada anteriormente alguns saberes sobre o continente africano que deixaram de ser conhecidos devido a dominação epistemológica do pensamento moderno ocidental. Vejamos esses conhecimentos:

1.Matemática: A invenção da matemática tem sua origem na pré-história africana. O mais antigo objeto matemático conhecido é o Osso de Lebombo e foi descoberto nas montanhas Lebombo da Suazilândia e datado com aproximadamente 35.000 a.C.

2.Medicina: Muitos tratamentos utilizados hoje em medicina moderna foram empregados pela primeira vez na África milênios atrás. O papiro de Edwin Smith é um texto sobre cirurgia e detalhes de observações anatômicas e exame, diagnóstico, tratamento e prognóstico de numerosas doenças. Foi provavelmente escrito por volta de 1600 a.C., mas é considerado uma cópia de vários textos anteriores.

3.Linguagem :O uso de estimativas apoiadas por evidências genéticas, arqueológicas, paleontológicas e outras, sugere que a língua provavelmente surgiu em algum lugar da África subsaariana durante a Idade da Pedra, daí as primeiras palavras de humanos foram faladas por africanos.

4.Arquitetura e Engenharia :O império africano do Egito desenvolveu uma vasta gama de estruturas diversas e grandes monumentos arquitetônicos ao longo do Nilo, entre os maiores e mais famosos dos quais são a Grande Pirâmide e a Grande Esfinge de Gizé (MACHADO, 2018 ).

Sabermos que no continente africano vestígios a respeito de conhecimentos 
matemáticos, linguísticos, da medicina, da engenharia e arquitetura entre outros compõem arquivos de saberes, de produção do conhecimento fundamentais a humanidade provam o quanto a invisibilidade de outras cosmovisões contribuiu para a desvalorização e para a inferioridade de povos que no entanto possuíam um alto grau de desenvolvimento mas que pela colonialidade, pelo capitalismo, pela dominação cultural, político, econômico e social não foram considerados dignos de possuir tais conhecimentos.

Precisamos descolonizar o saber já. Necessitamos romper com o epistemicídio. Para isso somos chamados a conhecer outras geografias do saber.

Para Adiche Chimamanda (2017), escritora nigeriana, conhecer apenas uma versão dos fatos representa um grande perigo a humanidade. É o que considera "o perigo da história única" que fez com que inúmeras nações, povos, territórios, culturas tivessem seus conhecimentos negados, silenciados e até mesmo exterminados.

Já Ribeiro $(2017,2018)$ nos alerta acerca do "lugar de fala". A colonialidade do saber determinou o conhecimento válido, legítimo onde sujeitos subalternos não possuíam o direito do discurso, da produção do conhecimento. Para a autora, quilombolas, ribeirinhos, mulheres, negros, homossexuais, latinos, indígenas precisam exigir seus espaços de fala, ter representatividade para que assim consigam descolonizar o saber e propor outras vertentes da história.

Para Crenshaw (2004) um olhar interseccional dos fatos ajuda a compreender como as opressões de raça, gênero, classe, sexual, religiosa e territorial por exemplo foram importantes para manter um projeto de colonialidade de saber. Com a intersecionalidade também podemos buscar alternativas para a superação da colonialidade e assim descolonizar o conhecimento propondo a intersecção dos saberes dos diversos povos e sujeitos para a solução de diversos problemas e superação dos desafios de nossos tempos.

Boaventura (2010) para a descolonização do conhecimento propõe uma epistemologia do sul, na qual possamos buscar outros territórios, sair de nossa zona de conforto e partirmos para outros espaços, para outros diálogos. E desta forma possibilitarmos novas conexões e explicações da realidade.

Novas geografias sejam elas ribeirinhas, quilombolas, periféricas, indígenas etc, tem muito a nos ensinar, a tornar este conhecimento descolonizado. Temos muito a aprender com o outro, pois o conhecimento está em todo lugar, todos nós produzimos conhecimentos. Por isso, vozes outras precisam ecoar. Isto é combater o epistemicídio. 


\section{CONSIDERAÇÕES FINAIS}

O extermínio de um conhecimento, o desaparecimento de uma cultura pode ser considerada um fato concreto se nesta sociedade existir a dominação de uma história única. No decorrer desta breve reflexão percebemos como a colonização a partir de um projeto de civilidade, permitiu a invisibilidade de povos/nações.

A existência de uma epistemologia dominante imposta pelo mundo moderno ocidental provocou o epistemicídio, a invisibilidade de saberes, suprimiu práticas e conhecimentos locais, tudo em prol de uma missão de homogeneização do mundo que reduziu a diversidade epistemológica porque deixou de valorizar diversas experiencias sociais.

Assim como Machado (2018) nos provocou no sentido de instigar com sua publicação a necessidade de sermos também protagonistas da história, assumindo o posto do "leão" que conta agora a sua versão dos fatos, também somos chamados a descolonizar o saber, ou seja, não permitirmos que apenas o "caçador" seja glorificado e conte apenas a sua versão.

Não podemos mais aceitar o assassinato e a recusa da produção do conhecimento de determinados povos, nações, territórios e sujeitos. É necessário que os grilhões se rompam, para isso valorizar conhecimentos provenientes também de camponeses, indígenas, ribeirinhos, quilombolas, gays, refugiados mulheres, negros são passos fundamentais para novas geografias do saber e consequentemente para a descolonização do conhecimento.

\section{REFERÊNCIAS BIBLIOGRÁFICAS}

ADICHIE, Chimamanda Ngozi. Para educar crianças feministas: um manifesto. Tradução: Denise Bottmann. - $1^{\mathrm{a}}$ ed. - São Paulo: Companhia das Letras, 2017.

CRENSHAW, Kimberle. A intersecionalidade na discriminação de raça e gênero. In: VV.AA. Cruzamento: raça e gênero. Brasília: Unifem. (2004).

DIAS. Leticia Otero. $O$ feminismo decolonial de Maria Lugones. $8^{\circ}$ ENEPED UFGD $5^{\circ}$ EPEX -Encontro de Ensino Pesquisa e Extensao. UEMS. Janeiro/2015.
GONÇALVES< Carlos Walter. Apresentação da edição em português. IN: LANDER, Edgardo. (Org) A colonialidade do saber: eurocentrismo e ciências sociais. Perspectivas latino americanas. Coleção Sul, CLACSO, Cidade Autónoma de Buenos Aires, Argentina. Setembro, 2005.

QUIJANO, Anibal. Colonialidade do poder, eurocentrismo e America latina. A Colonialidade do saber, eurocentrismo e Ciencias sociais. Perspectiva latinos americanos. Buenos Aires. CLACSO. (2005).

RIBEIRO, Djamila. $O$ que é lugar de fala? Belo Horizonte (MG): 
Letramento.2017.

, Quem tem medo do feminismo negro? Sao Paulo. Companhia das Letras. 2018.

SANTOS, Boaventura de Sousa e MENEZES, Maria Paula (Org). Epistemologias do Sul. São Paulo:
Cortez, 2010.

MACHADO, Carlos. Invenções africanas que mudaram o mundo Disponível em: https://revistaraca.com.br/invencoesafricanas-que-mudaram-o-mundo. Acesso em 08 de out. 2019.

GONÇALVES, J. S. FEITOSA, M. A. P. Descolonizar Já: Pontos em Debates Sobre o Epistemicídio .Complexitas - Rev. Fil. Tem. Belém, v. 4, n. 2, p. 40-47, jul./dec. 2019. Disponível em: http://www.periodicos.ufpa.br/index.php/complexitas/article/view/8054>. Acesso em: 30 de janeiro de 2020. 